\title{
FUNDAMENTOS ESTÉTICOS DA LITERATURA DE HORROR: A INFLUÊNCIA DE EDMUND BURKE EM H. P. LOVECRAFT
}

Júlio FRANÇA*

RESUMO: Este artigo pretende demonstrar (i) a influência exercida pela obra $A$ philosophical enquiry into the origin of our ideas of the sublime and beautiful, de Edmund Burke, sobre o ensaio de H. P. Lovecraft, Supernatural horror in literature e, conseqüentemente, (ii) a importância da teoria burkeana do sublime como fundamento da reflexão crítica contemporânea sobre a narrativa ficcional de horror.

PALAVRAS-CHAVE: Literatura de Horror; H.P.Lovecraft; Teoria do Sublime; Edmund Burke.

A reflexão crítica sobre a narrativa ficcional de horror tem, de modo mais ou menos consciente, assumido uma orientação aristotélica. Autores como Horace Walpole, Edgar Allan Poe e Stephen King, consagrados pela tradição, estão entre aqueles que pensam a criação literária por uma perspectiva que privilegia os efeitos de recepção e que concebem a obra literária de horror como um artefato produtor de uma emoção específica: o medo e suas variações. Tal descrição, contudo, é de caráter puramente formal; aponta os objetivos do escritor de horror, mas não os justifica, isto é, não legitima, esteticamente, a produção do medo.

Howard Phillips Lovecraft - reconhecido por um significativo número de autores contemporâneos como o mais influente escritor do gênero no século XX encontrou um caminho para essa legitimação, ao propor que a mais antiga e intensa emoção experimentada pelo ser humano é o medo, e sua forma mais antiga e intensa é a do medo do desconhecido. Tal asserção é fundada em seu entendimento de que o ser humano recordar-se-ia mais facilmente da dor e da ameaça da morte do que do prazer e que, conseqüentemente, o medo, por sua intensidade emocional, seria uma sensação legítima a ser produzida por obras de arte.

As idéias lovecraftianas são referência constante nos estudos sobre a narrativa ficcional de horror, mas não são exatamente originais: o presente artigo pretende demonstrar justamente a influência exercida pela obra de Edmund Burke - A philosophical enquiry into the origin of our ideas of the sublime and beautiful - sobre o

\footnotetext{
* Doutor em Literatura Comparada (UFF), e Professor Adjunto de Teoria da Literatura (UERJ).
} 
pensamento de H. P. Lovecraft e, deste modo, apresentar aquele que é provavelmente o mais importante fundamento da reflexão contemporânea sobre a narrativa de horror.

\title{
A potência do medo
}

É de Howard Phillips Lovecraft uma das mais extensas reflexões acerca da literatura de horror já produzida por um ficcionista. O ensaio Supernatural Horror in Literature começou a ser escrito em 1924, foi finalizado três anos depois e sofreu revisões constantes até que, em 1939, dois anos após a morte do autor, foi publicado em sua versão definitiva. No livro, Lovecraft escreve uma história do gênero, ao mesmo tempo em que defende uma estética da ficção do horror profundamente assentada em premissas burkeanas - muito embora não faça nenhuma menção explícita a Edmund Burke ao longo do texto.

O ensaio inicia-se com uma enunciação já célebre na tradição crítica da narrativa de horror:

\begin{abstract}
A emoção mais antiga e mais forte da humanidade é o medo, e o tipo de medo mais antigo e mais poderoso é o medo do desconhecido. Poucos psicólogos contestarão esses fatos e sua reconhecida verdade deve estabelecer, pra todos os tempos, a autenticidade e dignidade da ficção fantástica de horror como forma literária. (LOVECRAFT, 2007, p.13)5
\end{abstract}

Lovecraft apóia-se no que parece ser um truísmo, ao dizer que o mais antigo e intenso sentimento experimentado pelo ser humano é o medo, e sua forma mais antiga e intensa é a do medo do desconhecido. Na realidade, porém, está se apoiando, como veremos mais adiante, em teses desenvolvidas por Edmund Burke. Essas primeiras linhas já revelam que o ensaio, ao propor uma fundamentação estética, parte de um desejo de conferir genuinidade e dignidade à narrativa de horror, ciente da necessidade de justificar um gênero que estava - e ainda está - longe de desfrutar de uma aceitação unânime como legítima forma literária.

$\mathrm{Na}$ atitude combativa que marca já o primeiro parágrafo do ensaio, pode-se ver que Lovecraft identifica adversários da legitimidade da narrativa de horror tanto em "materialistas" quanto em "idealistas":

\footnotetext{
${ }^{5}$ Neste ensaio, utilizarei nas citações a recente tradução de Celso M. Paciornik de O horror sobrenatural na literatura.
} 
Contra ela [a autenticidade e dignidade da ficção fantástica de horror como forma literária] são desfechadas todas as setas de uma sofisticação materialista que se aferra aos acontecimentos externos e emoções corriqueiras, e de um idealismo ingênuo que despreza a motivação estética e pede uma literatura didática para 'elevar' o leitor a um nível adequado de pretensioso otimismo. (ibidem, p.13)

Malgrado tanto o desprezo "materialista" pelo caráter fantástico das histórias quanto a desaprovação "idealista" do horror como um tema estético - em favor de uma literatura didática mais "elevada" espiritualmente - a narrativa de horror, para Lovecraft, não apenas sobrevivia, mas vinha se aperfeiçoando, justamente por estar associada a mecanismos profundos e fundamentais do ser humano: o sentimento do medo, tomado como a mais potente emoção passível de ser experimentada pelo homem.

Embora o medo fosse um sentimento universal, sua produção através da narrativa ficcional de horror estaria condicionada a uma recepção com a necessária sensibilidade de experimentá-lo, isto é, a eficiência da ficção de horror estaria sujeita à predisposição do leitor:

O apelo do macabro espectral é geralmente restrito porque exige do leitor um certo grau de imaginação e uma capacidade de distanciamento da vida cotidiana. São relativamente poucos os que se libertam o suficiente do feitiço da rotina diária para responder aos apelos de fora. (ibidem)

O poder de atração da literatura de horror dependeria, pois, de um certo grau de imaginação de seu leitor, bem como de uma capacidade dele para se afastar das demandas da vida cotidiana. Ainda que admitisse serem poucos os que possuiriam tais qualidades, uma vez que os temas corriqueiros do dia-a-dia dominavam a maior parte da experiência humana, Lovecraft acreditava que mesmo nos indivíduos mais racionais residiria uma herança biológica capaz de ser ativada pelas narrativas que inspiram medo. Em outras palavras, todos teríamos, em potencial, uma predisposição para tais emoções:

(...) a sensibilidade está sempre em nós e, às vezes, um curioso rasgo de fantasia invade algum canto obscuro da mais dura das cabeças, de tal modo que soma nenhuma de racionalização, reforma ou análise freudiana pode anular por inteiro o frêmito do sussurro do canto da lareira ou do bosque deserto. Está presente nisso um padrão ou tradição psicológica tão real e tão profundamente enraizado na experiência mental quanto qualquer 
outro padrão ou tradição da humanidade; (...) uma parte integrada demais em nossa herança biológica mais profunda para perder sua contundência (...). (ibidem, p.14)

Lovecraft acredita que a predisposição ao horror seria um fator biológico no ser humano e remontaria a nossos primitivos antepassados, cujos instintos e emoções consistiam basicamente em respostas ao ambiente, condicionadas por estímulos de prazer ou de dor. Para o homem primitivo, o universo seria uma fonte inesgotável de experiências com o desconhecido. A imprevisibilidade da vida teria tornado os nossos antepassados reféns de uma natureza terrível e onipotente, tanto capaz de gerar graças quanto calamidades. Eram premiados ou punidos por razões que lhes eram misteriosas, pois pertenciam a esferas da existência sobre as quais nada sabiam.

Acredita Lovecraft que a experiência humana do sonho contribuiu ainda mais para solidificar a idéia da existência de outro mundo não material. As próprias condições de vida do homem primitivo eram ideais para fomentar a sensação de haver um outro plano, sobrenatural, e teriam tornado o ser humano hereditariamente suscetível a todo tipo de superstições. Por mais que a ciência moderna viesse conseguindo restringir a "zona do desconhecido" (ibidem, p.15) no campo da experiência humana, nosso inconsciente e nossos instintos estariam "fisiologicamente" (ibidem) ligados a essas crenças, a despeito do quanto possa se afastar a mente consciente das fontes do maravilhoso.

O pensamento lovecraftiano a respeito das origens primitivas de nossa predisposição ao horror aproxima-se bastante das reflexões de Sigmund Freud sobre o medo no campo da estética. A análise de experiências com o "estranho" levou o fundador da psicanálise a traçar paralelos entre o comportamento humano em relação ao medo e as antigas concepções animistas do universo:

É como se cada um de nós houvesse atravessado uma fase de desenvolvimento individual correspondente a esse estágio animista dos homens primitivos, como se ninguém houvesse passado por essa fase sem preservar certos resíduos e traços

\footnotetext{
${ }^{6} \mathrm{O}$ principal artigo freudiano sobre o tema do medo relacionado à estética é "Das Unheimliche", de 1919. Nele, Freud aborda o que considera um tema estético pouco abordado: o "estranho", ou "sinistro", uma experiência que, embora tenda a coincidir com outras capazes de despertar o medo, possuiria a peculiaridade de ser provocada por algo que é, de algum modo, familiar. O artigo foi traduzido para o inglês em 1924 e não é impossível que Lovecraft, que tinha conhecimento de alguns trabalhos de Freud, o tivesse lido.
} 
dela, que são ainda capazes de se manifestar, e que tudo aquilo que agora nos surpreende como "estranho" satisfaz a condição de tocar aqueles resíduos de atividade mental animista dentro de nós e dar-lhes expressão. (FREUD: 1996, p.257-8)

Para Freud, em nosso desenvolvimento como indivíduos vivenciaríamos uma fase, especificamente na infância, em que nossas atividades mentais se aproximariam das do homem primitivo: idéias de que o mundo é povoado por espíritos, crenças nas mais diversas técnicas mágicas, o assombro contínuo diante de um mundo repleto de proibições e ameaças. Através de um processo racional de educação, tais resquícios ancestrais foram sendo gradativamente reprimidos, mas permaneceriam, latentes, suscetíveis a serem ativados nas circunstâncias ideais:

Todas as pessoas supostamente educadas cessaram oficialmente de acreditar que os mortos podem tornar-se visíveis como espíritos, e tornaram tais aparições dependentes de condições improváveis e remotas. (ibidem, p.259-60)

Freud estava ciente de que uma das principais fontes do medo eram as experiências de algum modo relacionadas à morte - cadáveres, suposto retorno dos mortos, espíritos, fantasmas etc. Isso se deveria à limitada evolução do nosso conhecimento sobre tais assuntos: "Dificilmente", diz ele, "existe outra questão (...) em que as nossas idéias e sentimentos tenham mudado tão pouco desde os primórdios dos tempos (...) como a nossa relação com a morte" (ibidem, p.258). Para o ensaísta, a combinação entre "a força da nossa reação emocional original à morte e a insuficiência do nosso conhecimento científico a respeito dela" (ibidem) era a principal responsável pela intensidade peculiar das experiências que envolviam o sentimento do medo ${ }^{7}$ :

A biologia não conseguiu ainda responder se a morte é o destino
inevitável de todo ser vivo ou se é apenas um evento regular,
mas ainda assim talvez evitável, da vida. É verdade que a
afirmação "Todos os homens são mortais" é mostrada nos
manuais de lógica como exemplo de uma proposição geral; mas
nenhum ser humano realmente a compreende, e o nosso
inconsciente tem tão pouco uso hoje, como sempre teve, para a
idéia da sua própria mortalidade. (...) Uma vez que quase todos

\footnotetext{
${ }^{7} \mathrm{O}$ entendimento de Freud de que o mistério da morte é o principal combustível do sentimento de horror parece ter também influenciado diretamente a reflexão de Stephen King sobre a narrativa de horror ficcional (Cf. FRANÇA, 2008b).
} 
nós ainda pensamos como selvagens acerca desse tópico, não é motivo para surpresa o fato de que o primitivo medo da morte é ainda tão intenso dentro de nós e está sempre pronto a vir à superfície por qualquer provocação. (ibidem, p.259)

Se, para Freud, as idéias relacionadas à morte seriam o gatilho perfeito para ativar nossas crenças primitivas reprimidas, para Lovecraft, as barreiras em nossa mente racional poderiam ser superadas por um conjunto um pouco mais amplo de elementos, com os quais o ficcionista de horror precisaria lidar. Para demonstrar quais seriam esses recursos, o escritor norte-americano precisará lançar mão de outros pressupostos burkeanos.

\section{O medo cósmico}

$\mathrm{Na}$ seqüência de sua argumentação, Lovecraft aprofunda as relações entre a ficção de horror e as origens primitivas de nossas crenças em realidades sobrenaturais. Como os elementos relacionados aos aspectos positivos do desconhecido teriam sido, desde muito cedo na história do homem, capitalizados e formalizados pelos rituais religiosos convencionais, o lado mais sombrio e maligno dos mistérios cósmicos acabara sendo encampado pelas narrativas populares e folclóricas. $\mathrm{O}$ ensaísta aponta que especialmente na Idade Média, período de baixa difusão do conhecimento e assolada por pestes cujas causas eram desconhecidas, criou-se o ambiente adequado para fomentar "tanto entre letrados como entre pessoas incultas a mais inquebrantável fé em cada forma do sobrenatural, das doutrinas mais benévolas da Cristandade às aberrações mais monstruosas da bruxaria e da magia negra” (LOVECRAFT: 2007, p.21). Esse fértil campo da imaginação forneceu um vasto material aos narradores. Diante da pujança das narrativas sobrenaturais populares, Lovecraft surpreende-se com o tardio reconhecimento acadêmico do gênero, que só se dará com a ascensão do romance gótico, em fins do século XVIII.

Incerteza e perigo seriam os catalisadores das narrativas sobrenaturais populares. O desconhecido representaria uma fonte constante de possibilidades perigosas e malévolas. A combinação entre a sensação do perigo, a intuição do mal, o inevitável encanto do maravilhoso e a curiosidade possuiria uma vitalidade inerente à própria raça humana. O ensaísta entende que o fascínio das narrativas sobrenaturais, sobretudo aquelas cuja temática envolve elementos malignos, explica-se pela razão de a dor e

ameaça da morte serem sensações mais intensas para o ser humano do que o prazer. É 
fundado nessa premissa - burkeana, como veremos mais adiante - que Lovecraft pode afirmar que a literatura capaz de provocar o que chama de "medo cósmico" (ibidem, p.16) sempre existiu e sempre existirá. A efetividade desse tema poderia mesmo ser medida, pensa ele, ao se observar como autores que não se dedicam à literatura de horror produzem narrativas plenamente integradas ao gênero - um exemplo expressivo seria The turn of the screw [1898], de Henry James.

Note-se que Lovecraft dá ênfase a um certo tipo de narrativa de horror - a "literatura de medo cósmico", cuja característica principal é estar relacionada com os resquícios de nossa consciência primitiva, sempre suscetível a crenças em realidades obscuras, desconhecidas e à margem daquilo que entendemos por natural. Esse tipo específico de narrativa produtora do medo não deveria ser confundido "com um outro superficialmente parecido, mas muito diferente no âmbito psicológico: a literatura do simples medo físico e do horrível vulgar" (ibidem, p.16), tampouco com o chamado "conte cruel", denominação criada por Villiers de l'Isle-Adam para suas próprias narrativas, em que as emoções são alcançadas, na visão de Lovecraft, não pelo medo do sobrenatural, mas por "provações dramáticas, frustrações e horrores físicos pavorosos" (ibidem, p.59):

\begin{abstract}
A história fantástica genuína 8 tem algo mais que um assassinato secreto, ossos ensangüentados, ou algum vulto coberto com um lençol arrastando correntes, conforme a regra. Uma certa atmosfera inexplicável e empolgante de pavor de forças externas desconhecidas precisa estar presente; e deve haver um indício, expresso com seriedade e dignidade condizentes com o tema, daquela mais terrível concepção do cérebro humano - uma suspensão ou derrota maligna e particular daquelas leis fixas da Natureza que são nossa única salvaguarda contra os assaltos do caos e dos demônios dos espaços insondáveis. (ibidem, p.17) [Grifo meu, cf. nota 4]
\end{abstract}

Lovecraft avalia como esteticamente superiores as narrativas de horror que tomam como tema o desconhecido ou eventos que estejam para além das leis naturais e

\footnotetext{
${ }^{8}$ No original "The true weird tale". Lovecraft - ao contrário da injusta acusação que lhe foi feita por Tzvetan TODOROV (2007, p.41) - não está falando de "literatura fantástica", mas de um tipo específico de "literatura sobrenatural". As principais acepções de "weird" são "1. (frightening because it is) unnatural, uncanny or strange; 2. unconventional, unusual or bizarre" (Oxford Advanced Learners Dictionary. Oxford: Oxford University Press, 1989, p. 1448), isto é, a tradução por "fantástico" dada a carga conceitual que a palavra possui nos Estudos Literários, não parece ser adequada, pois conduz a um desentendimento quanto à especificidade das teses lovecraftianas.
} 
que privilegiam os efeitos do medo "cósmico" no leitor, em detrimento dos efeitos do medo "físico". O critério final de autenticidade de uma obra de horror não seria nem o enredo, nem mesmo a "qualidade" da narrativa, mas o tipo de sensação que ela é capaz de produzir (ibidem, p.16). Ele é categórico em defender que se deve julgar o conto sobrenatural não tanto em relação às intenções do autor ou aos mecanismos da intriga, mas sim em função da intensidade emocional que provoca.

(...) devemos julgar uma história fantástica9, não pela intenção do autor ou pela simples mecânica do enredo, mas pelo nível emocional que ela atinge (...). $\mathrm{O}$ único teste do realmente fantástico10 é apenas este: se ele provoca ou não no leitor um profundo senso de pavor e o contato com potências e esferas desconhecidas. (ibidem, p.17-8) [Grifos meus, conforme nota 4]

Lovecraft afirma que, por vezes, apenas certos fragmentos de uma obra são capazes de produzir os efeitos do medo cósmico, o que pode ocorrer mesmo à revelia das intenções de seu autor: “(...) boa parte da obra fantástica mais seleta é inconsciente, aparecendo em fragmentos memoráveis espalhados por material cujo efeito geral pode ser de molde muito diferente" (ibidem, p.16). Configura-se, deste modo, uma compreensão da literatura de horror centrada quase que exclusivamente na recepção. Os aspectos do processo literário relacionados aos propósitos do autor e aos traços formais da narrativa são colocados em segundo plano, diante do que Lovecraft considera ser o teste definitivo da narrativa de horror cósmico: saber se ela provoca ou não, no leitor, uma sensação profunda de pavor diante do contato com aquilo que é desconhecido.

\section{Lovecraft e a tradição crítica dos ficcionistas de horror}

O entendimento de Lovecraft corrobora os de Horace Walpole e de Edgar Allan Poe, no sentido de que os três pensam a narrativa como modos de produção de efeitos algo que tenho chamado de "tradição crítica dos ficcionistas de horror" (FRANÇA, 2008b). Em relação a esses seus antecessores, Lovecraft reconhece o "muito jovial e mundano" Horace Walpole como aquele que deu o impulso necessário para que a narrativa de horror se consolidasse como gênero fixo, embora não poupe adjetivos para

\footnotetext{
${ }^{9}$ No original "Weird tale", conforme nota 4.

${ }^{10}$ No original "Weird", conforme nota 4.
} 
depreciar The Castle of Otranto, que considera uma história sobrenatural "absolutamente inconvincente e medíocre":

A história - tediosa, artificial e melodramática - é ainda mais prejudicada por um estilo prosaico e ríspido, cuja jovialidade banal não permite, em nenhum momento, a criação de uma verdadeira atmosfera fantástica11. (LOVECRAFT: 2007, p.26) [Grifo meu, conforme nota 4]

Se não demonstra simpatia pela "simplória, afetada e absolutamente carente do verdadeiro horror cósmico" (ibidem, p.27) narrativa de Walpole, Lovecraft parece acreditar que The Castle of Otranto foi ao encontro de uma demanda reprimida, numa época em que as representações "realistas" pareciam haver superado as "imaginativas" no gosto literário. Ele simpatiza com o fato de que Walpole parece ter tido a consciência de que o maravilhoso encontrava receptividade em seu leitor não por seu absoluto caráter fictício, mas exatamente por causar dúvidas quanto à sua veracidade. Não apenas os leitores comuns, mas a própria crítica da época foi "enganada" pelo primeiro prefácio $^{12}$ de Walpole, e recebeu o romance, favoravelmente, como obra de um tradutor habilidoso. Quando, na segunda edição da obra [1765], Walpole confessa, em um novo prefácio, o caráter ficcional de The Castle of Otranto, os críticos atacaram então exatamente o caráter "romântico" (isto é, fantasioso) e absurdo do romance.

Na perspectiva lovecraftiana, a contribuição de Horace Walpole foi, sobretudo, a de ser um fundador, o que conseguiu ao

(...) criar um tipo inovador de cenários, personagens típicos e incidentes que, manipulados para melhor vantagem dos escritores mais naturalmente adaptados á criação fantástica13, estimularam o crescimento de uma escola imitativa do gótico que, por sua vez, inspirou os verdadeiros criadores de um terror cósmico - a linhagem de verdadeiros artistas que começa com Poe. (ibidem, p.27-8) [grifo meu, conforme nota 4]

\footnotetext{
${ }^{11}$ No original "Weird", conforme nota 4.

12 No prefácio à primeira edição da obra, Walpole utiliza o recurso ficcional do "antigo manuscrito": afirma que o romance seria, na verdade, a tradução de um original italiano, do século XVI, escrito em letras góticas, de autoria desconhecida.

${ }^{13}$ No original "Weird", conforme nota 4.
} 
Edgar Allan Poe - "a ele devemos a moderna história de horror em seu estado final e aprimorado" (ibidem, p.62) - pavimentou, segundo Lovecraft, o caminho aberto por Walpole. Único autor a ter um capítulo exclusivo no "Supernatural horror in literature", o escritor norte-americano é reconhecido por ter encontrado a forma ideal da narrativa de horror:

É verdade (...) que escritores que o sucederam podem ter apresentado contos isolados melhores que os seus, mas (...) precisamos compreender que foi somente ele que os ensinou, com exemplos e preceitos, a arte que eles, tendo o caminho aplainado à sua frente e com um guia explícito, foram capazes de levar a extensões maiores. (ibidem, p.61)

Para Lovecraft, Allan Poe teria conduzido a narrativa sobrenatural um passo adiante, pois compreendera "a base psicológica da atração do horror" (ibidem, p.62) ou, em outras palavras, entendera que a eficiência da ficção de horror estava na capacidade de produzir, no leitor, o medo. Era também mérito de Poe ter superado convenções literárias que consistiam em um entrave ao gênero, como a do final feliz, a da virtude recompensada, o didatismo moral vazio e o hábito dos autores de "imiscuir suas próprias emoções na história e se alinhar com os partidários das ideias artificiais da maioria" (ibidem).

Lovecraft admirava em Allan Poe "a impessoalidade essencial do verdadeiro artífice" (ibidem), isto é, a concepção poeana da criação literária como um artefato produtor de efeitos de recepção. O distanciamento com que abordava os temas de seus contos - fossem eles atrativos ou repulsivos, estimulantes ou deprimentes - e sua recusa em atuar como "um professor, simpatizante ou formulador de opinião" (ibidem) teria permitido a Poe perceber com clareza "que todas as fases da vida e do pensamento são temas igualmente propícios para o escritor" (ibidem).

As narrativas poeanas recobrem vários sub-gêneros não identificados com o medo cósmico, desde os contos de lógica e raciocínio, passando pelas grotesqueries e extravagâncias de influência hoffmanniana, até o terror psicológico não-sobrenatural. Allan Poe era para Lovecraft não apenas um modelo de escritor de temas sobrenaturais, mas de escritor tout court. Se em alguns contos Poe alcançou a essência da literatura de horror sobrenatural, teria sido devido a seu peculiar temperamento, que o inclinou a ser

(...) o intérprete daqueles poderosos sentimentos e frequentes ocorrências que acompanham a dor e não o prazer, a decadência 
e não o progresso, o terror e não a tranquilidade, e que são, no fundo, adversos ou indiferentes aos gostos e aos sentimentos superficiais ordinários da humanidade. (ibidem, p.62)

Se Allan Poe é explicitamente a principal influência literária de H. P. Lovecraft, Edmund Burke representa a influência filosófica implícita de sua reflexão crítica. É o que pretendo demonstrar a partir de uma exposição concisa da teoria burkeana do sublime.

\section{A teoria do sublime de Edmund Burke}

A história da teoria do sublime nos Estudos Literários começa com Peri Hypsous, de Longino, um tratado do século III sobre um dos estilos da retórica clássica. O texto foi redescoberto pela tradição ocidental em 1674, mas não causou maiores impressões, até ser recuperado por alguns seguidores de Boileau, quando provavelmente os dilemas e a ansiedade da modernidade nascente encontraram eco na obra de Longino.

A natureza do estilo sublime para Longino é a de conduzir ao êxtase e não à persuasão. O sublime é uma experiência de choque que provoca uma sensação de adynasía (impotência, indigência, impossibilidade) no leitor/ouvinte, diante das situações limites provocadas pelo impacto das paixões, das idéias ou das imagens apresentadas. Longino não duvida de que a arte da palavra seja a que mais se presta a alcançar o sublime, exatamente por poder superar os limites da própria arte enquanto mera técnica de representação da natureza. Nas artes plásticas, como a escultura por exemplo, o limite é o homem; mas o discurso - a literatura, como hoje entenderíamos deveria visar o sobre-humano.

Mas é somente na obra de Edmund Burke, A Philosophical Enquiry into the Origin of our Ideas of the Sublime and Beautiful (1757), que as relações entre o conceito de sublime e a literatura de horror podem ser aprofundadas. Para tanto, é necessário inicialmente compreendermos a peculiaridade de suas noções de prazer e de dor.

Para Burke, a dor não seria simplesmente a eliminação do prazer, tampouco o prazer seria o simples extinguir da dor. Tanto uma quanto o outro seriam sensações independentes. A cessação do prazer não conduziria imediatamente à dor, mas poderia afetar o espírito de três outros modos: (i) conduzindo-o à indiferença, no caso de o prazer cessar naturalmente, após ter-se prolongado por um certo período; (ii) 
conduzindo-o a uma sensação de inquietude que Burke chama de decepção, no caso de o prazer ser subitamente interrompido e; (iii) conduzindo-o ao pesar, no caso de o objeto do prazer estar irremediavelmente perdido, de modo a não haver mais como desfrutá-lo. Para Burke, nenhum desses sentimentos seria mais intenso do que a dor propriamente dita. Mesmo o mais agudo deles, o pesar, não se aproximaria da intensidade da verdadeira dor: "A pessoa pesarosa deixa-se dominar por sua paixão, abandona-se a ela, nela se compraz; mas isso nunca ocorre no caso da dor real, que ninguém jamais suportou voluntariamente durante muito tempo" (BURKE: 1993, p.46). Mesmo não sendo exatamente prazeroso, o pesar é uma sensação que mantém os aspectos mais agradáveis do objeto do prazer no pensamento: "no pesar, o prazer continua a predominar, e a angústia que sentimos não se assemelha à dor pura, que nunca deixa de ser detestável e da qual procuramos nos livrar tão logo quanto possível" (ibidem).

Da mesma forma, a diminuição da dor não conduziria ao prazer, mas a um sentimento de alívio que, embora agradável, não se confundiria com o prazer positivo. Burke chama de deleite ${ }^{14}$ essa sensação. Prazer, dor e indiferença seriam, portanto, sensações autônomas e possuiriam, portanto, suas próprias causas e conseqüências. Todas as nossas paixões 15 seriam por elas orientadas. Das três, a dor seria a emoção mais poderosa - eis aqui a tese lovecraftiana - e a ela estariam associadas as paixões relacionadas aos nossos instintos de autopreservação:

As idéias de dor, de doença e de morte enchem o espírito de intensos sentimentos de pavor; mas vida e saúde, não obstante nos proporcionem a sensação de prazer, não produzem tal impressão mediante o mero contentamento. Portanto, as paixões que estão relacionadas à preservação do indivíduo derivam principalmente da dor e do perigo e são as mais intensas de todas. (ibidem, p.47)

A preponderância das paixões relacionadas aos nossos instintos de autopreservação deve-se ao fato óbvio de que, para o desempenho de qualquer uma de nossas atividades, é fundamental estarmos vivos e saudáveis. Qualquer coisa que ponha em risco nossa vida ou nossa saúde nos afeta, portanto, de modo intenso. Por essa razão,

14 No original, "Delight".

15 Por "paixão" entenda-se aqui qualquer sentimento suficientemente intenso a ponto de ofuscar a razão. 
ainda que a dor seja entendida por Burke como a mais intensa de nossas sensações, a idéia da morte seria ainda mais poderosa. Uma vez que o risco da interrupção da vida é a ameaça derradeira aos nossos instintos de autopreservação, Burke supunha que o terrível poder da dor sobre nós adviesse de sua condição de "emissária" da "rainha dos terrores" (ibidem, p.48).

Dada a intensidade das sensações relacionadas à morte, a percepção da dor ou do perigo, quando o indivíduo não estivesse realmente em uma situação de perigo ou de dor, consistiria na matriz ideal para a experiência do sublime:

Tudo que seja de algum modo capaz de incitar as idéias de dor e de perigo, isto é, tudo que seja de alguma maneira terrível ou relacionado a objetos terríveis ou atua de um modo análogo ao terror, constitui uma fonte do sublime, isto é, produz a mais forte emoção de que o espírito é capaz. Digo a mais forte emoção, porque estou convencido de que as idéias de dor são muito mais poderosas do que aquelas que provêm do prazer. (ibidem, p.48)

As paixões relativas à autopreservação são meramente dolorosas quando estamos expostos às suas causas, porém, quando experimentamos sensações de dor e de perigo sem que estejamos realmente sujeitos aos riscos ${ }^{16}$, as paixões decorrentes do seu alívio tornam-se "deliciosas"17, isto é, produzem o prazer específico do deleite, conforme anteriormente conceituado - uma sensação prazerosa que não se confunde com prazer positivo, uma vez que é gerado a partir da dor.

Como seria possível, entretanto, experimentar uma sensação de dor ou de perigo não se estando, efetivamente, submetido às situações reais de risco? Para Burke, a resposta está relacionada a outros tipos de paixão, não àquelas ligadas aos instintos de autopreservação, mas às que estão associadas á necessidade humana da vida em sociedade - sobretudo o sentimento da simpatia:

(...) a simpatia deve ser considerada uma espécie de substituição, mediante a qual colocamo-nos no lugar de outrem e somos afetados, sob muitos aspectos, da mesma maneira que eles; de

\footnotetext{
${ }^{16}$ Burke é categórico nesse ponto “(...) é indiscutivelmente necessário que minha vida esteja a salvo de qualquer desastre iminente para que eu aufira deleite dos sofrimentos, reais ou imaginários, dos meus semelhantes, ou, enfim, de qualquer coisa advinda de outra causa" (BURKE: 1993, p.55).

${ }^{17}$ No original "Delightful".
} 
modo que essa paixão pode (...) partilhar da natureza daquelas relacionadas à autopreservação e, derivando-se da dor, ser uma fonte do sublime. (ibidem, p.52)

Seria através do princípio da simpatia que as artes representativas em geral conseguiriam produzir as paixões. Desgosto, infelicidade, a própria morte, todos motivos que causam aversão no plano da realidade, no plano da ficção seriam capazes de gerar, graças ao sentimento da simpatia, um intenso deleite.

Burke vê nessa atração humana pelo que é terrível - ele se refere à nossa curiosidade mórbida - um comportamento pré-racional, instintivo:

(...) não há espetáculo que busquemos com tanta avidez quanto o de alguma desgraça incomum e atroz; portanto, quer a desdita ocorra diante de nossos olhos, quer ela se passe na história, sempre nos provoca deleite. Ele não é puro, mas mesclado com um razoável mal-estar. $\mathrm{O}$ deleite que auferimos dessas cenas de grande sofrimento impede-nos de evitá-las, e a dor sentida induz-nos a consolar-nos a nós próprios ao fazê-lo àqueles que sofrem; esses impulsos ocorrem anteriormente a qualquer raciocínio, por um instinto que age sobre nós, segundo seus próprios desígnios, sem o concurso de nossa vontade. (ibidem, p.54)

\section{Sublimidade e horror}

Se a beleza é por Burke definida como uma qualidade social positiva, percebida por nossos sentidos e que inspiraria amor e afeição para tudo que fosse percebido como belo, o sublime é de ordem bem mais complexa. Enquanto uma é fundada no prazer, o outro relaciona-se com a dor e o deleite. Além disso, a sublimidade e o sentimento do horror estariam intimamente relacionados. $\mathrm{O}$ assombro produzido pela contemplação de manifestações naturais do sublime - o poder e a vastidão da Natureza, a infinitude do cosmos, a magnificência da idéia de Deus - viria sempre acompanhado de um certo grau de horror. Parte da força do efeito sublime está justamente no fato de que seu arrebatamento antecede o emprego da razão. Isso porque o medo, entre todas as paixões, é aquela que despoja o homem de suas capacidades de ação e de raciocínio. Sendo uma espécie de arauto da dor ou mesmo da morte, o medo pode ter um efeito de estupor, semelhante ao de uma dor aguda.

Dor e terror seriam equivalentes, mas com uma diferença importante: as causas da dor agem sobre o espírito através de uma intervenção no corpo, enquanto que as 
causas do terror afetam o corpo através de uma ação direta sobre o espírito. Burke procura demonstrar que o terror é "o princípio primordial do sublime" (ibidem, p.66). Um de seus argumentos é demonstrar como diversas línguas atestam a afinidade existente entre essas idéias e empregam a mesma palavra para se referir aos sentimentos de assombro ou admiração e os de terror:

Thámbos é, em grego, ou medo ou admiração; Deinós é terrível ou venerável; Hedéo, reverenciar ou temer. Vereor, em latim, significa o mesmo que Hedéo em grego. Os romanos usavam o verbo stupeo, um termo que designa enfaticamente o estado de um espírito tomado de espanto, para exprimir o efeito tanto de um simples medo, quanto de assombro; a palavra attonitus (atingido pelo raio) expressa também a afinidade entre essas idéias; e não apontam $\mathrm{o}$ francês étonnement e $\mathrm{o}$ inglês astonishment e amazement, de modo igualmente claro as emoções afins que acompanham o medo e a admiração? (ibidem)

Se o sublime está de fato relacionado ao terror e, portanto, por extensão, à dor, restaria saber qual o valor da experiência do sublime para o ser humano. A resposta de Burke é de cunho fisiológico. O exercício físico é a proteção do corpo humano contra os transtornos e as inconveniências dos estados prolongados de repouso e de inação. O esforço muscular associado à atividade corporal não deixa de vir acompanhado de um certo grau de dor, mas sem esse tipo de estímulo o ser humano ficaria debilitado e enfermo. De modo semelhante, se "a dor e o terror estão moderados a ponto de não serem realmente nocivos, se a dor não é levada a uma intensidade muito grande e se o terror não está relacionado à destruição iminente da pessoa" (ibidem, p.41), o exercício de nossas sensações e paixões é benéfico, além de possuir faculdade de produzir o prazer peculiar do "horror deleitoso" (ibidem).

\section{Lovecraft e o sublime}

Lovecraft não admite em sua doutrina da narrativa sobrenatural sua filiação às teorias do sublime. Todavia, parece explícita a dependência do seu pensamento a premissas burkenas, tais como a influência das sensações de prazer e dor na recepção das obras; o caráter pré-racional de nossas paixões; a potência do sentimento do medo; e, sobretudo, as semelhanças entre "horror cósmico" e "horror sublime".

Outras relações poderiam ser encontradas nas fontes do Sublime elencadas por Burke. Entre elas, algumas estão intimamente relacionadas com as temáticas e os 
enredos da narrativa de horror: a obscuridade; o pavor de algo desconhecido; a ameaça física da dor, do ferimento ou da aniquilação; a privação; a solidão; o silêncio ou a vacuidade; a percepção da imensidão ou da infinitude, entre outras. Em comum, todas essas percepções seriam capazes de produzir dor, medo ou terror e, conseqüentemente, o deleite.

Sobretudo a obscuridade merece ser aqui comentada, por sua proximidade com as noções lovecraftianas de desconhecido. A complexa idéia de obscuridade - que pode se referir a objetos que são ausentes de luz, de clareza ou mesmo de inteligibilidade - é indispensável na produção ideal do medo ou do horror. O conhecimento do perigo em toda a sua extensão faria desaparecer parte da apreensão por ele provocada:

\begin{abstract}
Qualquer pessoa poderá perceber isso, se refletir o quão intensamente a noite contribui para o nosso temor em todos os casos de perigo e o quanto as crenças em fantasmas e duendes, dos quais ninguém pode formar idéias precisas, afetam os espíritos que dão crédito aos contos populares sobre tais espécies de seres. (ibidem, p.66-7)
\end{abstract}

Em relação às artes da representação, Burke entendia que a sugestão era capaz de produzir efeitos de horror muito mais eficazes do que a explicitação18. Tal pensamento, claramente endossado por Lovecraft, influenciou muito mais do que sua reflexão crítica sobre a narrativa sobrenatural, tendo se convertido na diretriz essencial da prosa de ficção lovecraftiana - um excelente tema para um próximo ensaio.

\title{
Referências Bibliográficas:
}

BURKE, Edmund. A philosophical enquiry into the origin of our ideas of the sublime and beautiful. New York: Oxford University Press, 1990.

18 Burke exemplifica com uma passagem bíblica do Livro de Jó em que a sublimidade se deveria, fundamentalmente, à indefinição da aparição é descrita: "No horror duma visão noturna, quando o sono costuma ocupar os sentidos dos homens, assaltou-me o medo, e o tremor, e todos os meus ossos estremeceram. E ao passar diante de mim um espírito, os cabelos da minha carne se arrepiaram. Parou diante um, cujo rosto eu não conhecia, um vulto diante dos meus olhos, e ouvi uma voz como de branda viração" (Jô, IV, 13-16). Comenta Burke: "Desde o início, somos preparados com a máxima solenidade para a visão, somos primeiramente aterrorizados, antes mesmo que saibamos a causa obscura de nossa emoção; mas, quando essa causa grandiosa se mostra, o que é ela? Não é, envolta nas sombras de sua própria escuridão incompreensível, mais apavorante, mais impressionante, mais terrível do que a descrição mais vívida, do que a pintura mais exata poderiam talvez representar? Quando os pintores tentaram nos apresentar figuras bem definidas dessas idéias extremamente fantasiosas e terríveis, na minha opinião foram, na maioria das vezes, mal-sucedidos; tanto que nunca pude me decidir, com relação a todos os quadros que vi sobre o inferno, se o pintor tinha ou não um objetivo jocoso" (ibidem, p.70). 
FRANÇA, Julio. O horror na ficção literária; reflexão sobre o "horrível" como uma categoria estética. In: Anais do XI Congresso Internacional da Abralic. São Paulo, 2008a [no prelo].

Terror, Horror e Repulsa: Stephen King e o cálculo da recepção. In: . Anais do IV Painel "Reflexões sobre o insólito na narrativa ficcional”; tensões entre o sólito e o insólito. Rio de Janeiro, 2008b [no prelo].

FREUD, Sigmund. O estranho. In: Obras psicológicas completas de Sigmund Freud; edição standard brasileira. V. XVII. Tradução de Eudoro Augusto Macieira de Souza. Rio de Janeiro: Imago, 1996. pp.233-269.

LOVECRAFT, Howard Phillips. O Horror Sobrenatural em Literatura. Tradução de Celso M. Paciornik. Apresentação de Oscar Cesarotto. São Paulo: Iluminuras, 2007.

. Supernatural Horror in Literature. New York: Dover, 1973.

LONGINO. Do sublime. Introdução e notas de J. Pigeaud. Tradução Filomena Hirata. São Paulo : Martins Fontes, 1996.

TODOROV, Tzvetan. Introdução à literatura fantástica. Tradução de Maria Clara Correa Castello. $3^{\text {a }}$ Ed. São Paulo: Perspectiva, 2007. 